\title{
Compensated transnational surrogacy in Australia: time for a comprehensive review
}

\begin{abstract}
"Australia
needs to do

more to

ensure that

transnational

surrogacy

is not

eproductive desire, domestic legal restrictions and cost have made transnational surrogacy a lucrative industry. ${ }^{1}$ Arrangements usually proceed smoothly, but ethical and legal scrutiny of this practice is ongoing. Commissioning parents have allegedly abandoned well ${ }^{2}$ and unwell ${ }^{3}$ children born to surrogates overseas. Investigations into transnational surrogacy are numerous, yet we are no closer to an answer as to whether the current status quo is acceptable.
\end{abstract}

exploitative or

commodifying

of surrogates,

commis-

sioning

parents and

children"

Ainsley J Newson

PhD(Bioethics), LLB(Hons) $\mathrm{BSc}$ (Hons)

Centre for Values, Ethics and the Law in Medicine, University of Sydney, Sydney, NSW.

ainsley.newson@ sydney.edu.au

doi: 10.5694/mja15.00166

Surrogacy involves a woman (the surrogate) undertaking a pregnancy and giving birth where another individual or couple (the commissioner[s] or intended parent[s]) will parent the child. Where the pregnancy involves the surrogate's oocyte, it is termed genetic, partial or traditional surrogacy. ${ }^{4}$ Gestational or full surrogacy occurs when gametes from the intended social parents or a separate donor are used. Surrogacy arrangements that do not result in net financial gain for the surrogate are referred to as altruistic (or non-commercial ${ }^{4}$ ), although the distinction between reimbursement and payment is easily blurred. Altruistic surrogacy is rare in Australia, with only 36 live births in 2013. ${ }^{5}$ Compensated or commercial arrangements involve payment (beyond mere expenses) in exchange for services. This practice is precluded by law or regulation in all Australian jurisdictions. ${ }^{6}$

All forms of surrogacy give rise to ethical issues. ${ }^{6}$ Compensated surrogacy is, however, more ethically contentious than altruistic surrogacy, owing to concerns over exploitation and commodification of women, intended parents and children. ${ }^{4}$ Concerns about socioeconomic disparities exacerbate these issues. This article focuses on the ethics, law and policy of surrogacy as it applies to Australians commissioning a pregnancy in low-income countries for a fee: a practice that can be termed transnational compensated surrogacy.

\section{Regulation of transnational compensated surrogacy in Australia}

Surrogacy is not regulated uniformly in Australia, ${ }^{1}$ and state and territory regimes have been criticised for the complexities that current oversight gives rise to.?

Altruistic surrogacy is permitted in all Australian states and the Australian Capital Territory, albeit with restrictions in some jurisdictions. Commercial surrogacy is prohibited by statute in all states and the $\mathrm{ACT}$, although payment for reasonable expenses is allowed. ${ }^{8}$ The Northern Territory has no statutes governing surrogacy, although in order to gain accreditation from the Reproductive Technology Accreditation Committee (RTAC), clinics need to adhere to National Health and Medical Research Council (NHMRC) guidelines that veto commercial surrogacy. ${ }^{6}$ Draft revisions to the NHMRC

\section{Summary}

- Commercial or compensated surrogacy involves providing payment for a woman to gestate a fetus to term and then hand over the child to commissioning parent(s).

- Compensated surrogacy is currently restricted by law or regulation in all Australian states and territories.

- New South Wales, Queensland and the Australian Capital Territory also restrict commissioning transnational compensated surrogacy, although there is evidence that this is not acting as a deterrent.

- Ethical issues arising in transnational compensated surrogacy include concerns relating to exploitation, commodification and welfare.

- The current status quo is unsatisfactory on legal, ethical and practical grounds. It is time to openly debate how Australia should balance the desire for childbearing through surrogacy with the limited domestic availability of women willing to act as surrogates.

guidelines say little about transnational surrogacy other than to stipulate practice standards for Australian clinicians. ${ }^{4}$

Residents in New South Wales, Queensland and the ACT are liable to be charged with an offence if they engage in compensated surrogacy overseas. ${ }^{9}$ However, this does not appear to act as a deterrent ${ }^{10}$ and is difficult to enforce. ${ }^{1}$ Destination countries include Nepal, Mexico and the Ukraine. Thailand has recently restricted compensated surrogacy to heterosexual couples married for more than 3 years; one of the couple also requires Thai nationality (http://www.sbs.com.au/news/article/ 2015/07/31/new-thai-surrogacy-law-bans-foreigners). India has recently initiated similar legal reforms. ${ }^{11}$

Transnational surrogacy also has legal complexity for citizenship and legal parentage. Examples of children ending up stateless have been discussed in the literature. ${ }^{12}$ Obtaining legal parentage following surrogacy can also be complex and there is potential for legal disputes to arise. ${ }^{1,13}$

\section{The question of exploitation}

The NHMRC's draft revised ethical guidelines on assisted reproductive technology cite concerns over exploitation to condemn commercial surrogacy. ${ }^{4}$ The concern here is the wrongful or unfair use of a woman to have a child for another for payment. ${ }^{14,15}$ Focusing on women's reproductive labour to benefit a commissioning couple may also fail to show appropriate respect, ${ }^{16}$ particularly given 
the vulnerability and unequal bargaining power of those who act as surrogates. ${ }^{17}$

The financial gain from commercial surrogacy could also unjustifiably induce participation, particularly if there is evidence that financial rewards mean poorer women participate when they would not otherwise. ${ }^{17,18}$ This could also be framed as a concern over "an unfair 'disparity of value' ${ }^{\prime \prime 15}$ between the payment made and risks encountered.

A response might be that surrogacy is a contract just like any other, and we only need to ensure the arrangement is entered into autonomously and fairly, including appropriate consent. However, the practicalities of ensuring valid consent in a social context of deprivation and inequality are not simple. ${ }^{14}$ Further, a contract in which the subject of the exchange is a reproductive service may be ethically distinct from contracts that do not involve this type of exchange. Surrogacy impacts bodily integrity, is a constant commitment for the period of gestation, restricts behaviour, is risky (with potential lasting physical and emotional effects) and leads to the birth of a new individual.

It is also interesting to consider whether exploitation should be objectively or subjectively determined. Whittaker's work examining surrogacy in Thailand, for example, suggests that women do not see their role as exploitative; surrogacy is "described as a selfless act of Buddhist merit". ${ }^{19}$ However, Whittaker also comments that framing commercial surrogacy as meritorious may merely be a new form of exploitation. Any influence that payment has on these attitudes may also be relevant.

Evidence also suggests that there are practices that exploit women acting as surrogates in some overseas countries. Accounts describe unscrupulous operators motivated by profit, ${ }^{20}$ contracts being worded to exclude surrogate women from decision making, ${ }^{21}$ and there are concerns about ongoing medical care and advocacy during pregnancy and after the birth. ${ }^{19}$ There is some evidence of pressure being applied to women to act as surrogates to help provide for their families. ${ }^{21}$ Around two-thirds of the fees paid for transnational surrogacy goes to agents. ${ }^{22}$

It therefore seems that at least some current practices of compensated transnational surrogacy have legitimate exploitation concerns, which will render them ethically problematic if not addressed. On the other hand, surrogacy is but one example of wider problems of exploitation in the face of global inequities. ${ }^{14}$ We need to ask both whether (and if so, how) we can improve equality and women's status in transnational surrogacy contracts and how we can also improve surrogates' material circumstances, ${ }^{17}$ including ensuring the utmost medical care and appropriate action if harm occurs.

\section{The question of commodification}

Commodification can be defined as occurring when surrogates, the services they provide or the children who are born through surrogacy are wrongfully treated as commodities (a product that can be bought and sold). ${ }^{15}$ The draft NHMRC guidelines cite this as the second main ethical justification for condemning compensated surrogacy. ${ }^{4}$ Commodification questions arise in all paid surrogacy, but are particularly prevalent in transnational surrogacy due to disparities in relative wealth. Two main questions arise. First, is compensated transnational surrogacy "baby selling"? Second, does it commodify women?

Critics of compensated surrogacy often turn to claims based on "buying children". Article 2a of an Optional Protocol to the United Nations Convention on the Rights of the Child (ratified by Australia) includes any act of child transfer for remuneration in its definition of the sale of children, ${ }^{23}$ and some have suggested that legal difficulties in separating payment for a child and payment for reproductive services mean that surrogacy has to be a form of child purchase. ${ }^{15}$ Additionally, surrogacy contracts often include clauses such that less is paid if a live baby is not surrendered to the commissioning couple.

Wilkinson rejects the claim that surrogacy is "baby selling" on numerous grounds. ${ }^{14,15}$ One is that a surrogate does not own the baby (insofar as anyone can do this); the commissioning parents do. A handover clause also does not make surrogacy baby selling; it makes it a service contract with a success clause.

As to commodification, conceiving and bearing a child is an intimate process. ${ }^{24}$ Adding a price could mean that women become mere "wombs for rent" by their commissioners. Wilkinson replies that including a fee-paying aspect does not preclude treating surrogate women with respect. It is the inappropriate use of compensated surrogacy that is commodifying, not compensated surrogacy itself.

It might also be claimed that reproductive labour is just one of many processes for which financial exchange often takes place without demeaning outcomes. Placing children into the care of others, for example, is an intimate and valuable parenting activity for which payment is made. Moreover, not all women may value the intimacy of gestation and labour; or, if they do, they are willing to relinquish this value to another.

\section{Welfare concerns and obligations}

Concerns exist around parental obligation and child welfare after transnational surrogacy. For example, if an overseas surrogate is found to be carrying twins, should a commissioning couple take both children? What should happen when a commissioning couple separates during the pregnancy and neither wants the child?

The best interests of the child standard might help answer these kinds of questions. However, the standard itself is liable to criticisms, such as it being vague, or setting a standard that is too high, or being too relative to a particular culture - leaving no room for objective assessment. $^{25}$ It is difficult to define what is in the best interests of a child conceived via transnational 
compensated surrogacy. And it could also be claimed that meeting basic interests is enough.

An alternative approach might be to focus on parental obligations. These are applicable to those "who assume the role of a parent" or a person "who has a continuing obligation to direct some important aspect (or aspects) of a child's development". ${ }^{26}$ They include duties such as supporting a child's development, fulfilling the child's needs, showing respect, providing primary goods, fostering autonomy and providing advocacy. ${ }^{26,27}$

Commissioning parents would be subject to these parental obligations, as they have assumed a parental role. The obligation could also be said to be continuing, given that their actions have had a direct causal relationship to the child being born. Commissioning parents who have more children than they can look after or who abandon a child arguably have failed to uphold their parental obligations. The only way parental obligations might end is if a commissioning parent makes appropriate and legal arrangements for another to take on the role instead.

\section{Domestic compensated surrogacy?}

Proposed revisions to NHMRC guidelines maintain opposition to compensated surrogacy. ${ }^{4}$ However, Everingham and colleagues have claimed that the resulting exodus of Australians abroad is a failure of domestic policy. $^{10}$

How might we respond to this? First, it might be claimed that the status quo could be preserved, perhaps with increased visibility of altruistic surrogacy. However, this would mean that Australians continue to travel for surrogacy, with the risks that this entails, ${ }^{28}$ the ethical problems it results in and the possibility of prosecution.

An alternate option is to better regulate transnational surrogacy. But we know this is not acting as a deterrent and is poorly enforced. ${ }^{1,18}$ It may also lead to risks through concealing travel if it were enforced and would require complex agreements between nations.

Third, domestic compensated surrogacy could be sanctioned as a harm-minimisation approach. ${ }^{14,18}$ Supporters point to factors such as payment being just one factor involved in surrogacy and the inherent commercialisation of assisted reproduction in Australia. ${ }^{18}$ Regulations could be developed to regulate brokering, fair wages and advertising; the latter is already under consideration in NSW. ${ }^{29}$
A final option is to take a different ethical approach; for example, by promoting national self-sufficiency. ${ }^{24}$ This is based on ethical principles such as societal responsibility, solidarity and justice and would involve treating surrogacy in a manner similar to organ donation. However, promoting self-sufficiency does not address the existing low numbers of altruistic donors.

In 2015, the NHMRC invited public comment on fixed payment to Australian oocyte donors beyond reasonable expenses. ${ }^{4}$ The justification was that many Australians are now travelling abroad and are liable to receive risky or poor-quality treatment. This justification could be said to be a similar harm-minimisation approach to that suggested for surrogacy. ${ }^{14,18}$ We can therefore question why fixed payment is being considered for oocyte donation in Australia, but not surrogacy.

A nationally coordinated approach to surrogacy may now be on the horizon, with the announcement of a Commonwealth inquiry into surrogacy. ${ }^{30}$ The inclusion of "compensatory payments" in the terms of reference for the inquiry will hopefully facilitate a thorough and in-depth discussion of these issues nationally. The inquiry is due to report by 30 June 2016.

\section{Conclusion}

Transnational compensated surrogacy raises significant ethical and legal issues. It involves balancing surrogates' and children's welfare with commissioners' desires to parent. The present status quo in Australia, with its varying regulations, complexity over legal parentage and concerns over welfare, is problematic. Under both present and proposed regulations, compensated transnational surrogacy will likely continue. Australia needs to do more to ensure that transnational surrogacy is not exploitative or commodifying of surrogates, commissioning parents and children. Parental obligations should also be emphasised in debates over this practice.

Acknowledgements: I thank Professor Stephen Wilkinson, Dr Anthony Wrigley and Associate Professor lan Kerridge for helpful discussions during the preparation of this article.

Competing interests: No relevant disclosures.

Provenance: Commissioned; externally peer reviewed.

(c) 2016 AMPCo Pty Ltd. Produced with Elsevier B.V. All rights reserved.

References are available online at www.mja.com.au. 
1 Johnson L, Blyth E, Hammarberg K. Barriers for domestic surrogacy and challenges for transnational surrogacy in the context of Australians undertaking surrogacy in India. J Law Med 2014; 22: 136-154.

2 Ireland J. Fresh concerns over boy abandoned in India. Sydney Morning Herald 2015; 14 Apr. http://www.smh.com.au/ federal-politics/political-news/fresh-surrogacy-concernsover-boy-abandoned-in-india-20150414-1mjyj3.html (accessed Apr 2015).

$3 \mathrm{ABC} /$ Reuters. Baby Gammy: WA parents of girl born to Thai surrogate deny abandoning twin brother. $A B C$ News 2014; 5 Aug. http://www.abc.net.au/news/2014-08-04/ wa-couple-denies-they-abandoned-baby-gammy/ 5644850 (accessed Feb 2015).

4 National Health and Medical Research Council. Draft ethical guidelines on the use of assisted reproductive technology in clinical practice and research. Public consultation - 2015. Canberra: NHMRC, 2015. http://consultations.nhmrc.gov.au/ public_consultations/assisted-reproductive-tech (accessed Nov 2015).

5 Macaldowie A, Lee E, Chambers GM. Assisted reproductive technology in Australia and New Zealand 2013. Sydney: National Perinatal Epidemiology and Statistics Unit, University of New South Wales, 2015.

6 National Health and Medical Research Council. Ethical guidelines on the use of assisted reproductive technology in clinical practice and research (2007). Canberra: Australian Government, 2007. https://www.nhmrc gov.au/_files_nhmrc/publications/attachments/e78.pdf (accessed Nov 2015).

7 Millbank J. The new surrogacy parentage laws in Australia: cautious regulation or "25 brick walls"? Melb U L Rev 2011; 35: 165-207.

8 Assisted Reproductive Treatment Act 2008 (Vic), s 44; Family Relationships Act 1975 (SA), s 10G; Surrogacy Act 2010 (NSW), s 8; Surrogacy Act 2010 (Qld), s 56; Surrogacy Act 2012 (Tas), s 40; Surrogacy Act 2008 (WA), s 8; Parentage Act 2004 (ACT), s 41 .

9 Surrogacy Act 2010 (Qld), s 54; Surrogacy Act 2010 (NSW), s 11; Parentage Act 2004 (ACT), s 45.

10 Everingham SG, Stafford-Bell MA, Hammarberg $\mathrm{K}$. Australians' use of surrogacy. Med J Aust 2014; 201: 270-273. https://www.mja.com.au/journal/2014/201/5/ australians-use-surrogacy

1 Howard S. Proposed ban on foreigners using Indian surrogacy services sparks protests. BMJ 2015; 351: h5854.

12 Henaghan M. International surrogacy trends: how family law is coping. Aust J Adoption 2013; 7. http://www.nla.gov.au/ openpublish/index.php/aja/article/viewFile/3188/3713 (accessed Nov 2015).

13 Smith S, Hawley S. Australian surrogacy laws a ticking time bomb, children risk growing up in limbo, senior judges warn. $A B C$ News 2014; 9 Oct. http://www.abc.net. au/news/2014-10-09/chief-justice-warns-surrogacylaws-are-a-ticking-time-bomb/5801430 (accessed Jan 2015).
14 Wilkinson S. Exploitation in international paid surrogacy arrangements. J Appl Philos 2015; Jul 14 [Epub ahead of print]. doi: 10.1111/japp.12138.

15 Wilkinson S. Bodies for sale: ethics and exploitation in the human body trade. London: Routledge, 2003.

16 Anderson E. Is women's labor a commodity? Philos Public Aff 1990; 19: 71-92.

17 Ballantyne A. Exploitation in cross-border reproductive care. Int J Fem Approaches Bioeth 2014; 7: 75-99.

18 Millbank J. Rethinking "commercial" surrogacy in Australia. J Bioeth Inq 2015; 12: 477-490.

19 Whittaker A. Merit and money: the situated ethics of transnational commercial surrogacy in Thailand. Int J Fem Approaches Bioeth 2014; 7: 100-120.

20 Crockin SL. Growing families in a shrinking world: legal and ethical challenges in cross-border surrogacy. Reprod Biomed Online 2013; 27: 733-741.

21 Centre for Social Research. Surrogate motherhood - ethical or commercial. Vasant Kunj (India): CSR, 2012. http://www. womenleadership.in/Csr/SurrogacyReport.pdf (accessed Jan 2015)

22 Nye C, Patel S. The fraught world of UK surrogacy. BBC News Magazine 2014; 21 Aug. http://www.bbc.com/news/ magazine-28864973 (accessed Jan 2015).

23 United Nations General Assembly, Optional Protocol to the Convention on the Rights of the Child on the Sale of Children, Child Prostitution and Child Pornography, A/RES/54/263. http://www.ohchr.org/Documents/Professionallnterest/ crc-sale.pdf (accessed Jan 2015).

24 Martin D, Kane S. National self-sufficiency in reproductive resources: an innovative response to transnational reproductive travel. Int J Fem Approaches Bioeth 2014; 7: $10-44$

25 Hale B. Regulation of international surrogacy arrangements: do we regulate the market, or fix the real problems? Suffolk Transnat L Rev 2013; 36: 501-526.

26 Blustein J. Parents and children: the ethics of the family. New York: Oxford University Press, 1982.

27 Hartwig MJ. Parenting ethics and reproductive technologies. J Soc Philos 1995; 25: 183-202.

28 Stafford-Bell MA, Everingham SG, Hammarberg K. Outcomes of surrogacy undertaken by Australians overseas. Med J Aust 2014; 201: 330-333. https://www.mja.com.au/ journal/2014/201/6/outcomes-surrogacy-undertakenaustralians-overseas

29 Marriner C. NSW considers allowing couples to advertise for surrogates. Sydney Morning Herald 2015; 20 Sep. http://www. smh.com.au/nsw/nsw-considers-allowing-couples-toadvertise-for-surrogates-20150918-gjq9ga.html (accessed Oct 2015).

30 Brandis G. Inquiry into surrogacy [media release]. 3 Dec 2015. Canberra: Attorney-General's Department. https://www. attorneygeneral.gov.au/Mediareleases/Pages/2015/ FourthQuarter/3-December-2015-Inquiry-into-surrogacy.aspx (accessed Dec 2015). 